\title{
VITAMIN D SUPPLY IN HEALTHY WOMEN WITH DIFFERENT REPRODUCTIVE STAGES: IS THERE ANY RELATIONSHIP WITH DBP LEVELS?
}

\author{
E. Toldy ${ }^{1,6}$, Z. Löcsei ${ }^{2}$, D. Horváth ${ }^{2}$, Cs. Koppány ${ }^{3}$, K. Kovács ${ }^{1}$, E. Tancsics ${ }^{1}$ and B. Kalman ${ }^{4}$, K. Rácz
}

Central Laboratory ${ }^{1}$ and $1^{\text {st }}$ Department of Medicine ${ }^{2}$, Department of Gynecology ${ }^{3}$, Center for Molecular Medicine ${ }^{4}$, Markusovszky Teaching Hospital of County Vas, Szombathely, Institute of Internal Medicine of Semmelweis University, Budapest ${ }^{5}$ and Department of Practical Diagnostics, Faculty of Health Science, University of Pecs ${ }^{6}$, Szombathely, Hungary

\section{Background:}

The total 25-hydoxy-vitamin-D (t-25OHD) level reflects the supply of vitamin $\mathrm{D}$, but is also influenced by the levels of 25OHD binding proteins (DBP). The DBP level rises during endogenous and exogenous estrogen excesses. However, it is unknown as to what degrees of $\mathrm{t}-25 \mathrm{OHD}$ level alterations may be expected.

We aimed studying t-25OHD and bioavailable 25OHD (bio-25OHD) levels in healthy females with different reproductive ages.

\section{Investigated cases}

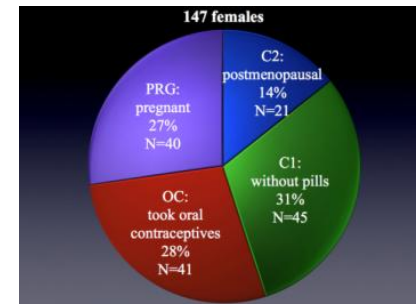

The women were divided into four groups depending on the degree of their estrogens levels: 126 healthy young women (age: $35.3 \pm 15.9$ years) were sorted into three subgroups: OC, C1 and PRG (see figure). An older control group (C2: age: $68.5 \pm 14.5$ years) of 21 postmenopausal women was also included.

\section{Analytical methods:}

$\mathrm{t}$-25OHD and intact parathormon (PTHi) were measured by protein binding- and immunometric- assays (Cobas e411, Roche). Total protein (TP), Albumin (Alb) and Ca levels were measured with colorimetric methods (Modular, Roche), and the proteins were investigated by electrophoresis. The Vitamin $\mathrm{D}$ binding protein (DBP) was assessed by immunoturbidimetric assay (Dako). Bio$25 \mathrm{OHD}$ and albumin - corrected $\mathrm{Ca}(\mathrm{CaAlb})$ were calculated.

\section{Results:}
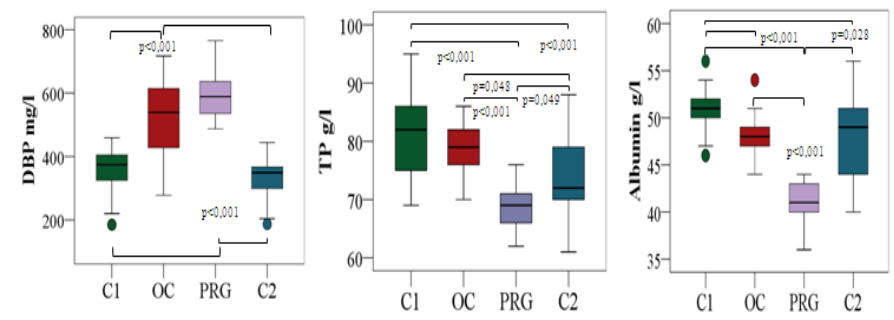

The highest levels of DBP were found in the PRG and OC groups with lowest TP and Alb concentrations. We did not find significant correlation between t-25OHD and DBP. Positive correlation ( $r=0.49$, $\mathrm{p}<0.05$ ) was observed between $\mathrm{t}-25 \mathrm{OHD}$ and Alb levels in $\mathrm{C} 2$ only.
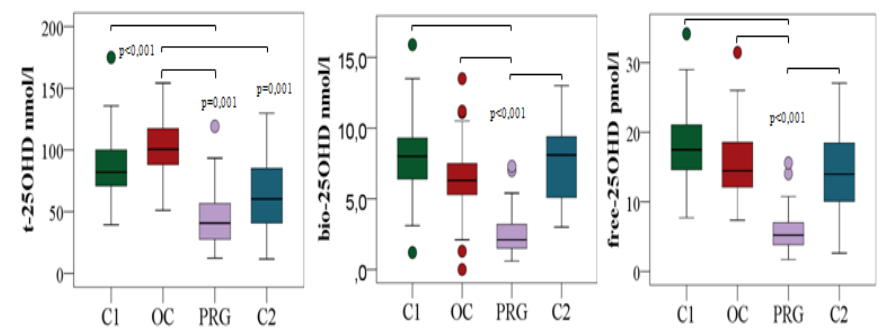

Levels of t-25OHD were highest in the OC, and lowest in the PRG group. However, bio- and free-25OHD levels were lower in the OC than in the $\mathrm{C} 1$ group.
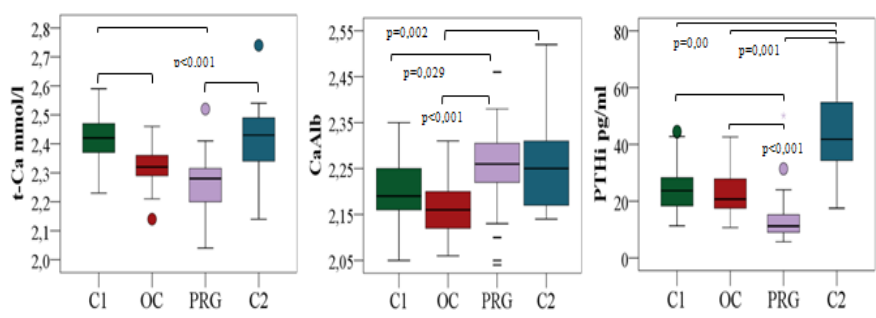

The highest CaAlb levels were observed in PRG with the lowest PTHi. However, the physiological associations between PTHi and bio-25OHD levels were true in $\mathrm{C} 1$ and $\mathrm{C} 2$. Significant associations were observed between $\mathrm{t}-25 \mathrm{OHD}$ and PTHi levels in all groups $(\mathrm{C} 1$ : $\beta=-0.29 p<0.05 ; C 2: \beta=-0.62 p<0.01$; OC: $\beta=-0.36 p<0.05$ ) except in the PRG group.

There was no association between t-25OHD and CaAlb levels, while a correlation was detected between bio-25OHD vitamin and $\mathrm{CaAlb}$ levels $(\beta=0.53 \mathrm{p}<0.05)$ in the $\mathrm{C} 2$ group only.

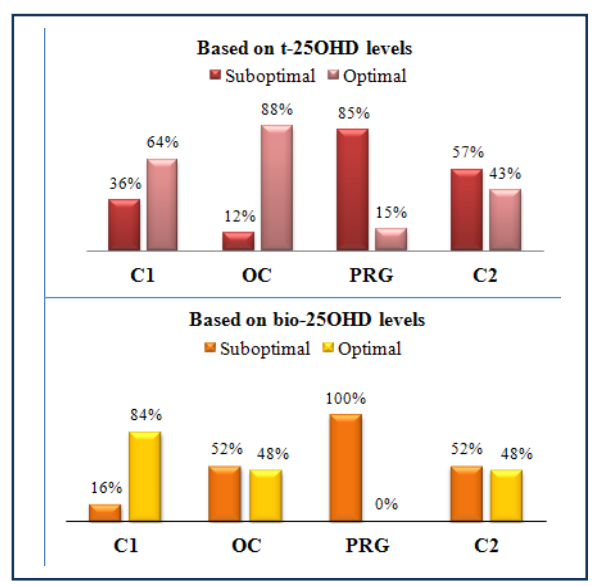

Based on the t-25OHD levels, only $12 \%$ of women in the OC, but $36 \%$ of women in the $\mathrm{C} 1$ group had suboptimal $(<75 \mathrm{nmol} / \mathrm{l})$ vitamin D supply. The bio-25OHD values reflect suboptimal $(<6.4 \mathrm{nmol} / \mathrm{l})$ vitamin supply most frequently $(51 \%)$ in the OC and least frequently in the $\mathrm{C} 1$ group $(15 \%)$.

\section{Conclusions:}

$\checkmark$ t-25OHD and DBP levels may disproportionally change.

$\checkmark$ Estimates of the vitamin D supply are influenced by the 25OHD fraction especially in case of estrogen excess.

$\checkmark$ We suggest quantifying the bio-available 250HD fraction in such cases.

$\checkmark \quad$ A possible cause of the frequently detected suboptimal vitamin D supply in association with increased estrogen excess may be related to an increased tissue consumption of the vitamin $\mathrm{D}$.

$\checkmark \quad$ The exact cut off values of vitamin D supply needs revisions in these circumstances. 